\title{
2020 - the year of the nurse and midwife: a call for action to scale up and strengthen the nursing and midwifery workforce in the Eastern Mediterranean Region
}

\author{
Ahmed Al-Mandhari, ${ }^{1}$ F Gulin Gedik, ${ }^{2}$ Awad Mataria, ${ }^{3}$ Arwa Oweis ${ }^{4}$ and Rana Hajjeh ${ }^{5}$
}

${ }^{1}$ Regional Director; ${ }^{2}$ Coordinator, Health workforce Development; ${ }^{3}$ Director, Health Systems and Innovation; ${ }^{4}$ Regional Advisor, Nursing and Midwifery; ${ }^{5}$ Director of Programme Management; World Health Organization Regional Office for the Eastern Mediterranean, Cairo, Egypt. (Correspondence to: F Gulin Gedik: gedikg@who.int).

Citation: Al-Mandhari A; Gedik FG; Mataria A; Oweis A; Hajjeh R. 2020 - the year of the nurse and midwife: a call for action to scale up and strengthen the nursing and midwifery workforce in the Eastern Mediterranean Region. East Mediterr Health J. 2020;26(4):370-371 https://doi. $\operatorname{org} / 10.26719 / 2020.26 .4 .370$

Copyright (C) World Health Organization (WHO) 2020. Open Access. Some rights reserved. This work is available under the CC BY-NC-SA 3.0 IGO license (https://creativecommons.org/licenses/by-nc-sa/3.o/igo)

The World Health Organization (WHO) has declared 2020 as the Year of the Nurse and the Midwife. World Health Day on 7 April is dedicated to supporting nurses and midwives and highlights the central role of these professions in advancing universal health coverage, achieving healthrelated sustainable development goals, and the Eastern Mediterranean Region Vision 2023: Health for All by All (1).

This year, we sadly mark World Health Day in the face of the devastating COVID-19 pandemic, which has brought to attention more than ever the crucial and invaluable role of health workers, who are working tirelessly day and night to care for patients and save lives. In fighting COVID-19, not only might they become infected and put their own lives at risk, but they also face distress and burnout because of long working hours. In addition, many health workers have to be away from their homes for prolonged periods, for fear of putting their own families at risk of acquiring the infection. Even before the pandemic, the safety and security of health workers in the Eastern Mediterranean Region has been a significant concern, as more than half of the countries of the Region face acute and protracted crises, and 70$80 \%$ of total recorded attacks on health facilities globally occur in the Eastern Mediterranean Region.

Nurses and midwives make up more than $50 \%$ of the health workforce. Multiple studies have revealed the important role of well-educated nurses to address the rise in infectious as well as chronic noncommunicable diseases, in addition to their substantial contribution to improve maternal, infant and child health (2-5). Commitments to strengthen nursing and midwifery have been provided over the years by the World Health Assembly and the Eastern Mediterranean Regional Committee. However, despite this highlevel commitment, the Region continues to face deep challenges in ensuring adequate nursing capacity. The State of World Nursing 2020 Report (6), launched on World Health Day, highlights the global shortage of 5.9 million nurses, with the Eastern Mediterranean Region accounting for $17 \%$ of this global shortage. While the global density of nurses is 36.9 per 10 ooo population, for the Region it is only 15.6 nurses (6).

Although the number of nursing education programmes and nursing graduates have increased over the past few decades, the density of nurses in the Region has not changed in the majority of Member States, and has even declined in 11 out of 22 countries since 2010. Compared to a global average of 22.6 nurse graduates per 100000 population, there are only 7.1 nurse graduates per 100000 population in the Eastern Mediterranean Region - the lowest among all WHO regions. Moreover, in many countries medical graduates outnumbered nursing and midwifery graduates in 2016, thus exacerbating the gap in the skills mix (7).

In order to address the shortage by 2030 , the total number of nurse graduates needs to increase by $10 \%$ per year on average. In addition, there needs to be an improved capacity to employ and retain these graduates by providing them with adequate incentives (6). The Report on the State of World Nursing 2020 estimates that an additional investment of US\$ 10 per capita is needed for nursing education in low- and middle-income countries, a small price to pay for such a highly needed health care skill set.

Advocacy is important to improve the numbers as well as the public perception for nurses and midwives. A three-year global Nursing Now campaign (2018-2020) has been initiated to raise the profile and status of nurses, and influence policy-makers to support nurses and build a global movement (8). Promoting nursing and midwifery as a career choice is also expected to lead to improved public perception, attractiveness and increased enrolment in the nursing and midwifery professions (9).

Despite the continued global and regional efforts to address these challenges, progress in scaling up nursing and midwifery has been slow in the Eastern Mediterranean Region. Therefore, in 2019 the Regional Committee for the Eastern Mediterranean adopted a resolution calling for action to strengthen the nursing workforce in the Region. This call for action, based on a systematic comprehensive approach, emphasized 
primary care nursing by defining and expanding nurses' roles and scope of practice in order to maximize the utilization of their capacities. Thus, nursing education requires reorientation to respond to countries' needs and governments must be committed to invest in education, employment and retention of nurses and midwives. Since health systems in the Region are overburdened by growing demands resulting from population increase, ageing and decreased funding, it is important that nurses and midwives become central members of health teams and key promoters of health and well-being. For this to happen, we need relevant regulatory frameworks, appropriate financing systems and adequate information systems.

In the midst of the COVID-19 pandemic that has already affected the lives of so many health workers, acknowledging and investing in the health workforce, especially nurses and midwives, is crucial (10). The Year of the Nurse and the Midwife provides immense opportunity to take forward the call for action in the Region and enhance the health workforce development agenda.

\section{References}

1. World Health Organization Regional Office for the Eastern Mediterranean (WHO/EMRO). Eastern Mediterranean Region Vision 2023: Health for all by all -a call for solidarity and action, Cairo: WHO/EMRO; 2018 (http://www.emro.who.int/about-who/ vision2023/vision-2023.html, accessed 1 April 2020).

2. United Nations Children's Fund (UNICEF). At least one in four children live in poverty in the Middle East and North Africa. Geneva: UNICEF; 15 May 2017. (https://www.unicef.org/press-releases/least-one-four-children-live-poverty-middle-east-and-northafrica, accessed 27 March 2020).

3. Speybroeck N, Kinfu Y, Dal Poz MR, Evans DB. Reassessing the relationship between human resources for health, intervention coverage and health outcomes. Geneva: World Health Organization; 2006 (https://pdfs.semanticscholar.org/fb21/eb31a783e802b2869f291ad29c8obf26ffo4.pdf, accessed 27 March 2020).

4. Discoll A, Currey JGM, Davidson PM. Changes in health service delivery for cardiac patients: implications for workforce planning and patient outcomes. Aust Crit Care. 2013;26(2):55-7. https://doi.10.1016/j.aucc.2012.08.001.

5. Persson LÅ, Nga NT, Målqvist M, Hoa DTP, Eriksson L, Wallin L, et al. Effect of facilitation of local maternal-and-newborn stakeholder groups on neonatal mortality: cluster-randomized controlled trial. PLoS Med. 2013;10(5):e1001445. https://doi.10.1371/ journal.pmed.1001445.

6. World Health Organization. State of the world's nursing 2020 report. Geneva, World Health Organization; 2020.

7. World Health Organization Regional Office for the Eastern Mediterranean (WHO/EMRO). Regional health observatory. Data repository. Health workforce: nursing and midwifery by country. Cairo: WHO/EMRO; 2020. (http://www.emro.who.int/entity/ statistics/regional-health-observatory.html, accessed 20 March 2020).

8. Nursing Now [website] (www.nursingnow.org, accessed 28 March 2020).

9. Masih S, Gulzar L. Nurses' self-perception about their public image in a metropolitan city, Karachi. J Dow Uni Health Sci. 2016;10(2):70-74.

10. Editorial, COVID-19: protecting health-care workers. Lancet, Vol 395 March 21, 2020. (http://www.thelancet.com, accessed 1 April 2020). 